\title{
Chapter 6 \\ Intellectual Capital and Challenges of Organizations in the Twenty-First Century
}

\author{
Muhammad Khalique \\ Universiti Malaysia Sarawak, Malaysia \\ Shazali Abu Mansor \\ Universiti Malaysia Sarawak, Malaysia \\ Abu Hassan bin Md. Isa \\ Universiti Malaysia Sarawak, Malaysia \\ Jamal Abdul Nassir bin Shaari \\ Universiti Malaysia Sarawak, Malaysia
}

\begin{abstract}
In the present century, intellectual capital is recognized as the most important and strategic asset for organizations. Intellectual capital is mainly based on knowledge and useful information. Intellectual capital is playing a critical role to create value from the combination of tangible and intangible assets to enhance the performance of organizations. This chapter looks at the concept and application of intellectual capital and its associated challenges of organizations in a competitive environment. More specifically, this chapter highlights the relationship of intellectual capital with the performance of organizations of various sectors. The relationship of intellectual capital was supported by empirical studies which were done by various renowned researchers in the intellectual capital field. In addition, this chapter discusses the various major components and models of intellectual capital.
\end{abstract}

\section{INTRODUCTION}

Over the past two decades, the concept and applications of intellectual capital have got overwhelming attention from academicians, researchers and practitioners. Nowadays, intellectual capital has become a critical asset for organizations to mange and utilizes its resources in order to gain a sustainable competitive edge. Intellectual capital appears as one of the principal asset in the current and future success of the organizations, particularly in high-tech sector. The multidisciplinary nature of

DOI: $10.4018 / 978-1-4666-4530-1 . c h 006$

Copyright (c) 2014, IGI Global. Copying or distributing in print or electronic forms without written permission of IGI Global is prohibited. 